\title{
Genetic properties of bla CTX-M, bla SHV and bla TEM genes in ESBL producing $E$. coli clinical isolates
}

\author{
V. Tavadze ${ }^{1^{*}} \mid$ T. Koiava ${ }^{2} \mid$ M. Nagervadze ${ }^{3} \mid$ M. Koridze $^{4} \mid$ H. Ferreira ${ }^{5} \mid$ L. \\ Akhvlediani $^{6}$ | R. Khukhunaishvili ${ }^{7}$
}

${ }^{1} \mathrm{PhD}$ student of Batumi Shota Rustaveli State University, Georgia;

${ }^{2}$ Assistant professor of Batumi Shota Rustaveli State University, Faculty of Natural Sciences and Health Care, Georgia;

${ }^{3}$ Associate Professor of Batumi Shota Rustaveli State University, Faculty of Natural Sciences and Health Care, Georgia

${ }^{4}$ Professor of Batumi Shota Rustaveli State University, Faculty of Natural Sciencesand Health Care, Georgia;

${ }^{5}$ University of Porto, Pharmacy Faculty, Department of Microbiology, Portugal; Health Superior Institute of Alto Ave, Portugal;

${ }^{6}$ Professor of BAU International University, Batumi, School of Medicine and Health Sciences and Associate Professor of Batumi Shota Rustaveli State University, Faculty of Natural Sciences and Health Care, Georgia

${ }^{7}$ Professor of Batumi Shota Rustaveli State University, Faculty of Natural Sciences and Health Care, Georgia.

\begin{abstract}
Extended spectrum $\beta$-lactamase (ESBL) producing Escherichia coli is a serious global public health problem that requires timely and accurate control of resistant strains. This is the first report on the detection of resistant E. coli isolates in hospitals of Adjara.

We studied the genetic profile of Escherichia coli isolates producing ESBL isolated from biological samples of patients with suspected nosocomial infection in four general hospitals in Adjara region (Georgia). Identification of resistant genes was performed by multiplex PCR and reverse hybridization. Genes of the class ESBL TEM, ESBL SHV and CTX-M were found in these samples as a result of molecular studies of genes causing genotypic correlation and resistance. Molecular genetic testing of phenotypically resistant strains of penicillin, cephalosporins of the 3rd and 4th generations and inhibitors revealed a wide range of antibiotic resistance genes with bla CTX-M, bla TEM, bla SHV, and in two samples with genes, of ESBL class bla TEM type mutated genes: bla TEM AS104 E, bla TEM AS 238 G, bla TEM AS238 S genes.
\end{abstract}




\section{1 | INTRODUCTION}

$\mathrm{N}$ osocomial or healthcare associated infections' (HAI) are considered a public health problem. These infections occur worldwide both in developed and developing countries. The prevalence of HAIs in developed countries varies between $3.5 \%$ and $12 \%$ whereas in developing countries it is around $5.7 \%$ to $19.1 \%$. European Centre for Disease Prevention and Control has reported 7.1\% as the prevalence of HAIs and it estimates around 4 million patients are being affected every year in Europe (1)

Nosocomial infections are acquired during hospital treatment or in a hospital environment. Infections caused by gram-negative bacteria have features that are of particular concern. These organisms are highly efficient at up-regulating or acquiring genes that code for mechanisms of antibiotic drug resistance, especially in the presence of antibiotic selection pressure. Furthermore, they have available to them a plethora of resistance mechanisms, often using multiple mechanisms against the same antibiotic or using a single mechanism to affect multiple antibiotics (2) . One such infecting agent, Escherichia coli, the most common Gram-negative pathogen in humans, harbors many virulence genes that enable it to become pathogenic (3) E. coli is an effective marker for antibiotic resistance in each community (4) .

Extended spectrum $\beta$-lactamase (ESBL)-producing E.coli are typically resistant to extended spectrum cephalosporins and monobactams (aztreonam). These bacteria are of increasing concern as ESBL encoding genes are usually harbored on plasmids, which co-harbor multiple resistance genes (5). The most frequently encountered ESBLs belong to the CTX-M, SHV, and TEM families. Among the many ESBLs described in a variety of pathogens, CTXM, TEM, and SHV types proved to be the most successful in terms of promiscuity and dissemination across various epidemiological niches (6) .

Most ESBLs are derivatives of TEM or SHV enzymes. There are now 138 TEM and 63 SHV-type $\beta$-lactamases. With both of these groups of enzymes, a few point mutations at selected loci within the gene give rise to the extended-spectrum phenotype. TEM- and SHV-type ESBLs are most often found in E.Coli and other genera of Enterobacteriaceae. TEM-1 can hydrolyze penicillin and early cephalosporins. The amino acid substitutions that occur within the TEM enzyme occur at a limited number of positions. Several amino acid residues are especially important for producing the ESBL phenotype when substitutions occur at that position. They include glutamate to lysine at position 104, arginine to either serine or histidine at position 164, glycine to serine at position 238 , and glutamate to lysine at position 240 . The combinations of these amino acid changes result in various alterations in the ESBL phenotypes. It has been suggested that the naturally occurring TEMtype ESBLs are the result of fluctuating selective pressure from several $\beta$-lactams within a given institution rather than selection with a single agent (7)

Unlike the TEM-type $\beta$-lactamases, there are relatively few derivatives of SHV-1 Furthermore, the changes that have been observed in blaSHV to give rise to the SHV variants occur in fewer positions within the structural gene. The majority of SHV variants possessing an ESBL phenotype are characterized by the substitution of a serine for glycine at position 238. A number of variants related to SHV5 also have a substitution of lysine for glutamate at position 240. It is interesting that both the Gly238Ser and Glu240Lys amino acid substitutions mirror those seen in TEM-type ESBLs. The serine residue at position 238 is critical for the efficient hydrolysis of ceftazidime, and the lysine residue is critical for the efficient hydrolysis of cefotaxime (8) .

CTX-M enzymes are plasmid-based encoded cefotaxime's that constitute the fast growing family of ESBLS (9) . Thus far, 172 CTX-M variants have been reported. CTX-M has been divided into six groups (CTX-M-1, CTX-M-2, CTX-M-8, CTX-M9, CTX-M-25, and KLUC. In most clinical isolates

Supplementary information The online version of this article (https://doi.org/10.15520/mcrr.v4i1.157) contains supplementary material, which is available to authorized users.

Corresponding Author: V. Tavadze

PhD student of Batumi Shota Rustaveli State University, Georgia; 


\section{MANUSCRIPT CENTRAL}

CTX-M-1 group is the most frequent CTX-M type and has been reported in Enterobacteriaceae isolates from many regions of world $[(4),(10),(11)]$. It is necessary to know the frequency of strains carrying genes encoding ESBLs in hospitals in order to formulate a policy of empirical therapy in high-risk units where infections due to resistant organisms are much higher $[(10),(11)]$.

Microbial resistance through ESBL has been recognized globally and now ESBLs are a problem throughout the world [10,11].

Data on nosocomial ESBL infections in hospitals in the Autonomous Republic of Adjara (Georgia) were first published in 2016 (12). However, data on nosocomial infections caused by strains resistant to $E$. coli are still scarce in this region. Molecular genetic mechanisms of resistance have not been established.

This study includes the genetic profile of multidrugresistant E.coli strains, which are widespread in hospitals of this region.

\section{2 | MATERIALS AND METHODS}

Molecular identification phenotypically ESBL positive $E$. coli strains were performed by reverse hybridization using the ESBL kit (Autoimmune Diagnostic $\mathrm{GmbH}$ ). This kit is based on multiplex PCR, which is preceded by reverse hybridization using oligonucleotide probes. The PCR reaction is performed using an N-Mix. The resulting biotilinated amplicons are examined by a hybridization test. During hybridization, the amplicons attach to genetic probes that are attached to the strips. A highly specific washing procedure ensures that the hybrids will remain as long as the probe sequence is $100 \%$ complementary to the DNA amplicons. Alkaline phosphatase bound to a streptocide (sulfanilamide) is attached to the biotylinated hybrids and this complex is manifested during the color reaction upon addition of the NBT/BCIP substrate. Biotinylated amplicons are characterized by a hybridization reaction with SSOP for beta lactamases and controls, which are immobilized on a nitrocellulose membrane in a different format, presented as linear. DNA extraction from biological materials was performed using a kit
(Gene MATRIX Viral RNA/DNA Purification Kit) manufactured by EUR $x$. The extraction stage consisted of several steps - lysis - proteins contained in existing samples, their elimination using washing buffers, and obtaining pure nucleic acids in the elution step. To detect the genes under study, pairs of specific primers were used. Ready mixture for PCR reaction PCR was performed in $30 \mu \mathrm{l}$ mixture contained $2 \mathrm{mmol} \mathrm{MgCl}$, single PCR buffer, 0.1 mmol each dNTP, $0.3 \mu \mathrm{mol}$ F-primer, $0.3 \mu \mathrm{mol}$ Rprimer, 5\% 1.3U / T1 TaqDNA polymerase DMSO (Sigma) and $15 \mathrm{ng}$ DNA.

Identification of gene was conducted with a pair of primer. The amplification was performed according to conditions which are shown in Table 1

TABLE 1: PCR conditions for amplifying genes by polymerase chain reaction

\begin{tabular}{|c|c|c|c|c|}
\hline \multicolumn{2}{|c|}{ Genes/PCR stage } & \multirow{2}{*}{$\begin{array}{l}\text { temper- } \\
\text { ature } \\
94^{\circ} \mathrm{C}\end{array}$} & \multirow{2}{*}{$\begin{array}{l}\text { time } \\
10 \\
\min \end{array}$} & $\begin{array}{l}\text { cy- } \\
\text { cle }\end{array}$ \\
\hline \multirow{7}{*}{$\begin{array}{l}\text { Multiplex } \\
\text { TEM, } \\
\text { SHV, } \\
\text { CTY_M }\end{array}$} & Hot start & & & \\
\hline & Cycle & $94^{\circ} \mathrm{C}$ & 40 & \\
\hline & Denaturation & & sec & 30 \\
\hline & Cycle & $60^{\circ} \mathrm{C}$ & 40 & \\
\hline & Anneling & & sec & \\
\hline & $\begin{array}{l}\text { Cycle } \\
\text { Exstension }\end{array}$ & $72^{\circ} \mathrm{C}$ & $\begin{array}{l}1 \\
\min \end{array}$ & \\
\hline & $\begin{array}{l}\text { Final } \\
\text { extension }\end{array}$ & $72^{\circ} \mathrm{C}$ & $\begin{array}{l}7 \\
\min \end{array}$ & 1 \\
\hline
\end{tabular}

\section{3 | RESULTS AND DISCUSSION}

Recently, the number of nosocomial infections caused by resistant strains of E.coli has increased (13). Numerous studies confirm that the formation of antibiotic-resistant forms of $E$. coli, in particular to beta-lactam antibiotics, is associated with prolonged and uncontrolled use of antibiotics (14). It is believed that ESBL resistance is caused by the formation of point mutations TEM and SHV types in genes. Although in the recent period, the cases of resistance caused by genes of the CTX-M family have increased significantly (3) , (15) ]. To determine the role of E.coli in the etiology 


\section{E. COLI CLINICAL ISOLATES}

of nosocomial infections, our study examined samples taken from patients suspected of nosocomial infection. A total of 304 samples were examined. $E$. coli was isolated from various biological materials - urine, sputum, blood, cerebrospinal fluid from a wound. Washes from catheters were also examined.

In two investigated strains (N438 and N361), several resistance determinants were simultaneously revealed: CTX-M, TEM AS 104 E, TEM AS 164 R, TEM AS 238 G, TEMAS $238 \mathrm{~S}$ and SHV AS 238/240. Mutant forms of the TEM type genes of the EBLS class: TEM AS 104 E, TEM AS 238 G, TEMAS $238 \mathrm{~S}$ carry point mutations at positions 104, 164, and 238, respectively. Here we would like to highlight the genetic determinant TEMAS $238 \mathrm{~S}$ (mutation Gly238Ser), identified in our studied samples. The enzyme encoded by this gene works equally well and easily cleaves cefotaxime and ceftazidime, while the second, sulfur-containing beta-lactamase-producing enzyme, the TEM AS 164 $\mathrm{R}$ gene (Arg164Ser mutation) is more active than ceftacid.

It should be noted that from two isolates of resistant $E$. coli, isolated from two different medical institutions, almost all EBLS genes were found. This case suggests that strains of the same robust genetic profile may circulate in different hospitals and cause the spread of nosocomial infections.

Thus, genes have been identified for both broad spectrum beta-lactamases (wild type) and extended spectrum genes (ESBL) that cause beta-lactam ring rupture and ultimately lead to antibiotic resistance.

The discovery of E. coli resistance genes producing ESBL poses a risk of spreading antibiotic-resistant E. coli strains among hospitalized patients. It is necessary to develop measures for the timely detection and accurate control of resistant strains. E. coli was identified in 47 samples by standard bacteriological methods (plating on nutrient media followed by separation from pure culture). Antibiotic sensitivity was defined as antibiotics for cephalosporins, sulfonamides, tetracyclines, aminoglycosides, carbapenems, and quinolones. In our study, all strains showing resistance to beta-lactam antibiotics were tested for beta-lactamase production. Multiple resistance was observed in E. coli isolates following an antibiotic resistance profile study. Phenotypic test showed that $88 \%$ of $E$. coli isolates produce ESBL.

To identify the blaCTX-M, bla TEM, blaSHV genes, molecular genetic analysis of ESBLresistant strains was carried out. Analysis by multiplex PCR allowed us to simultaneously obtain amplifiers of the genes of interest to us. PCR identification of genes was carried out with a specific pair of primers: for blaCTXM: R5'-AAAAATCACTGCGCCAGTTC-3'F 5 '- AGCTTATTCATCGCCACGTT-3'; for blaTEM: R 5'-AAACGCTGGTGAAAGTA-3'; F5'TAATCAGTGAGGCACCTATCTC-3', for bla $\boldsymbol{S H} \boldsymbol{V}:$ R 5'-TTATCTCCCTGTTAGCCACC-3'; 5'TGCTTTGTTATTCGGGCCAA-3'.

To determine the resistance mechanisms of TEM type beta lactamases are especially interesting, since the coding genes are the result of one of the long evolutionary processes and are most often susceptible to mutation. The beta-lactamase type SHV-1 is no less interesting, since the coding genes of this enzyme are localized both on the bacterial chromosome and on plasmids.

As a result of the hybridization reaction on the nitrocellulose membrane, multiple PCR amplicons blaCTX-M , blaTEM, blaSHV genes were fixed in different positions, which are shown in Figure 1.

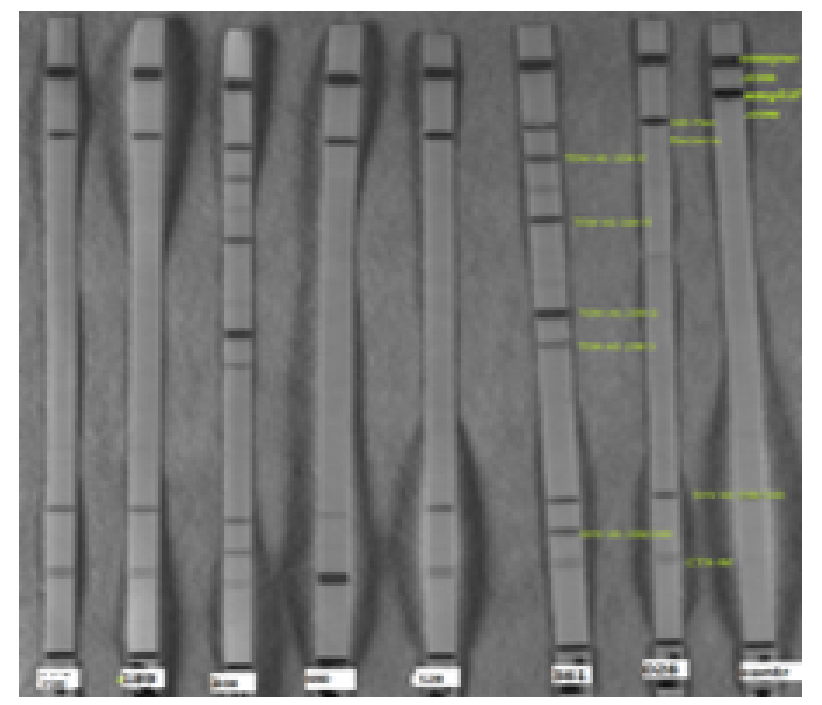

FIGURE 1: ESBLdetection of E. coli genes in isolates by reverse hybridization

Based on the obtained analysis results, we can assume that the resistance of the studied stains was 


\section{MANUSCRIPT CENTRAL}

simultaneously determined by the presence of several genetic determinants. Both broad (wild type) and extended spectrum (ESBL) beta lactamase were identified that cause the breakdown of the beta lactam ring and are ultimately responsible for antibiotic resistance.

In all studied strains, SHV AS 238/240 and CTX$M$ type mutations were recorded. SHV mutation caused by amino acid substitutions (G238 $\wedge \mathrm{S} / \mathrm{A}$ and E240 $\wedge$ K) causes an expansion of the spectrum of substrate specificity for cephalosporins, in particular for ceftazidime.

In two investigated strains (438 and 361) several resistance determinants were simultaneously revealed: CTX-M, TEM AS 104 E, TEM AS 164 R, TEM AS 238 G, TEMAS $238 \mathrm{~S}$ and SHV AS 238/240. Mutant forms of genes of the TEM type of the EBLS class: TEM AS 104 E, TEM AS 238 G, TEM AS $238 \mathrm{~S}$ carry point mutations at positions 104,164 and 238 , respectively. Here we would like to highlight the genetic determinant TEMAS $238 \mathrm{~S}$ (mutation Gly238Ser), identified in our studied samples. The enzyme encoded by this gene works equally well and easily cleaves cefotaxime and ceftazidime, while the second, sulfur-containing beta-lactamase-producing enzyme, the TEM AS 164 R gene (Arg164Ser mutation) is more active than ceftacid.

It should be noted that from two isolates of resistant E. coli (438 and 361), isolated from two different hospitals, almost all EBLS genes were found. This case suggests that strains of the same robust genetic profile may circulate in different hospitals and cause the spread of nosocomial infections.

Thus, genes have been identified for both broad spectrum beta-lactamases (wild type) and extended spectrum genes (EBLS), which cause beta-lactam ring rupture and ultimately lead to antibiotic resistance.

\section{4 | CONCLUSION}

Finding ESBL-producing genes of $E$. coli poses a risk of spreading antibiotic-resistant $E$. coli strains among hospitalized patients. It is necessary to develop measures for the timely detection and accurate control of resistant strains.

\section{REFERENCES}

1. Mehboob HAFKR, editor. Nosocomial infections: Epidemiology, prevention, control and surveillance //Asian Pacific Journal of Tropical Biomedicine. vol. 7.

2. M Y, Umar MI, Suleiman K. Indigenous commercial drinks as potential sources of extended spectrum $\beta$-lactamases (ESBLS) producing organisms in Kano, Nigeria. Int J Biomed Health Sci. 2010;6:103-108.

3. Moghaddam MMN, Beidokhti SH, Jamehdar M, Ghahraman; 2014.

4. Ghorbani-Dalini S, Kargar M, Doosti A, Pejmanabbasi, Meysamsarshar. Molecular Epidemiology of ESBL Genes and Multi-Drug Resistance in Diarrheagenic Escherichia Coli Strains Isolated from Adults in Iran. Iran J Pharm Res. 2015;14:1257-1262.

5. Johnson JR, Johnston B, Clabots C, Kuskowski MA, Castanheira M. Escherichia coliSequence Type ST131 as the Major Cause of Serious Multidrug-ResistantE. coliInfections in the United States. Oxford University Press (OUP); 2010. Available from: https://dx.doi. org/10.1086/653932. doi:10.1086/653932.

6. Rahman S, Ali T, Ali I, Khan NA, Han B, Gao J;. Available from: https://doi.org/10.1155/ 2018/9519718.

7. Patricia A Bradford Extended-Spectrum $\beta$ Lactamases in the 21st Century: Characterization E, Detection of This Important Resistance //ThreatClin Microbiol Rev-2001 Vol 14 NP-. Bradford Extended-Spectrum $\beta$-Lactamases in the 21st Century: Characterization, Epidemiology, and Detection of This Important Resistance //ThreatClin Microbiol Rev- 2001;14:933-951.

8. Huletsky A, Knox JR, Levesque RC. Role of Ser-238 and Lys-240 in the hydrolysis of 


\section{E. COLI CLINICAL ISOLATES}

third-generation cephalosporins by SHV-type beta-lactamases probed by site-directed mutagenesis and three-dimensional modeling. Journal of Biological Chemistry. 1993;268(5):36903697. Available from: https://dx.doi.org/10. 1016/s0021-9258(18)53748-0. doi:10.1016/s00 21-9258(18)53748-0.

9. Zhao WH, Hu ZQ. Epidemiology and genetics of CTX-M extended-spectrum $\beta$-lactamases in Gram. Critical Reviews in Microbiology. 2013;39:79-101.

10. Oteo J, Navarro C, Cercenado E, DelgadoIribarren A, Wilhelmi I, Orden B, et al. Spread of Escherichia coli Strains with High-Level Cefotaxime and Ceftazidime Resistance between the Community, Long-Term Care Facilities, and Hospital Institutions. Journal of Clinical Microbiology. 2006;44(7):2359-2366. Available from: https://dx.doi.org/10.1128/jcm.00447-06. doi:10.1128/jcm.00447-06.

11. Steward CD, Rasheed JK, Hubert SK, Biddle JW, Raney PM, Anderson GJ, et al.. Characterization of Clinical Isolates of Klebsiella pneumoniae from 19 Laboratories Using the $\mathrm{Na}$ tional Committee for Clinical Laboratory Standards Extended-Spectrum -Lactamase Detection Methods. American Society for Microbiology; 2001. Available from: https://dx.doi. org/10.1128/jcm.39.8.2864-2872.2001. doi:10. $1128 / j \mathrm{~cm} .39 .8 .2864-2872.2001$.

12. Steward CD, Rasheed JK, Hubert SK, Biddle JW, Raney PM, Anderson GJ, et al.. Character- ization of Clinical Isolates of Klebsiella pneumoniae from 19 Laboratories Using the National Committee for Clinical Laboratory Standards Extended-Spectrum -Lactamase Detection Methods. American Society for Microbiology; 2001. Available from: https://dx.doi. org/10.1128/jcm.39.8.2864-2872.2001. doi:10. $1128 / \mathrm{jcm} .39 .8 .2864-2872.2001$.

13. Koiava T, Gonçalves D, Palmeira J, Arobelidze K, Tediashvili M, Akhvledianil, et al.; 2016.

14. Ramadan AA, Abdelaziz NA, Amin MA, Aziz RK. Novel blaCTX-M variants and genotypephenotype correlations among clinical isolates of extended spectrum beta lactamase-producing Escherichia coli. Springer Science and Business Media LLC; 2019. Available from: https://dx. doi.org/10.1038/s41598-019-39730-0. doi:10.1 038/s41598-019-39730-0.

15. Tadesse DA. Antimicrobial drug resistance in Escherichia coli from humans and food animals. vol. 18. United States. Available from: https: //doi.org/10.3201/eid1805.111153.

How to cite this article: V.T., T.K., M.N., M.K., H.F., L.A., R.K. Genetic properties of bla CTX-M, bla SHV and bla TEM genes in ESBL producing $E$. coli clinical isolates. JOURNAL OF MEDICAL CARE RESEARCH AND REVIEW. 2020;480-484. https:/ /doi.org/10.15520/mcrr.v4i1.157 